\title{
Experimental research on a grid device for the kinetic energy charge dissipation of mud-flows
}

\author{
G. De Martino, F. De Paola, G. Marini \& A. Ranucci \\ Department of Hydraulic, Geotechnical and Environmental Engineering, \\ University of Naples Federico II, Italy
}

\begin{abstract}
A particular grid device for kinetic energy dissipation of a mud-flow is proposed, which is already usefully employed for stilling work to service dam drainages. In this paper, the results of experimental research on a prototype realized in the Laboratory of the Department of Hydraulic and Environmental Engineering G. Ippolito are presented, with the aim of also investigating the employment of the aforesaid grid device for the dissipation of the kinetic charge of a fast mud-flow, which is a natural extreme event. The experimental installation consists of a steel pond, equipped with a particular pump group made for the purpose, and is able to raise mud-flows up to $30 \mathrm{l} / \mathrm{s}$ up to a maximum height of approximately $12 \mathrm{~m}$ and the aforesaid flows, by means of a slide, are directed to the device. The fast mud-flow has been reproduced by means of a mixture of water and carbonate, which is insoluble in water, characterized from a $\mathrm{d}_{50}$ equal to $0.0013 \mathrm{~mm}$. During the tests different values of volume concentration have been adopted of between $50 \%$ and $70 \%$, and it has been possible to control the mixture by means of continuous measures of specific weight and viscosity. The results have shown the effectiveness of the device in the presence of flows characterized with elevated Froude numbers in particular, and a beneficial effect has been induced from an obstruction wall positioned on the extremity of the grid and also by varying the full bend behind the wall (and so the empty-full ratio of the device is between $0.20-0.30$ ), evidencing rollers that increase the total dissipative capacity of the device, which has turned out to be equal to approximately $85 \%$ in terms of kinetic charge.
\end{abstract}

Keywords: hydro-geological risk, energy dissipator, mud-flows, structural measures. 


\section{Introduction}

The calamitous events consequent to landslides, fast mud-flows or floods, even if it is possible to consider them as extreme natural events, have assumed a frequency for which the necessity of a structural, and not just structural measures for the mitigation of the hydro geological risk, is presented.

As far as, in particular, the structural measures for the defense from fast mudflows are concerned, the relative works introduce many more complex problems than those classic hydraulic systems (as an example the city water-drainage system) through the lack of consolidated planning criteria [2]:

- for the non-classical aspects of such measures;

- for the complexity involved to simulate these extreme phenomena with physical or mathematical models;

- for the different modalities of beginning;

- for the limited actual knowledge of the fast mud-flow mechanics.

Moreover, while for the classical hydraulic works it is possible to define a design event with a prefixed return period, for the mud-flows is not possible to define such an event because this does not depend exclusively on the hydrological sizes.

The structural measures can be subdivided into active and passive: the first, assigned to the prevention of the mobilization phenomena of the mass, that is to the reduction of the entity of the soil volumes moved and transported down-river. The second, faced to assure the protection of the risk mud-flows areas, as well as the build-up storage of the mud and expansion areas located immediately before the inhabited zones and such to assure the disconnection between these and the depositors from which the mud-flows could be originated.

In the present work the employment of a particular grid device for the kinetic charge dissipation of fast mud-flows characterized from elevated kinetic degrees is proposed, eventually for use as an anti mud-flow structure to build-up mud storage, while estimating the effectiveness by means of experimental research still in progress.

\section{Bottom grid dissipator}

The grid bottom dissipators are born essentially as a disposal means to clear water. These, if well designed, offer a considerable dissipation of the kinetic charge of a flow with very elevated energy, as an example, where there is an escape from the weir flood of an artificial lake. The operation principle is based on the fact that these measures impose a double direction change to the flow by means of the same flows through a pierced slab constituting the grid.

The principal element that constitutes these structures is a channel (generally with a horizontal slope, or just a little inclined in the adverse flow direction), on whose bottom is situated a series of holes in number and sufficient dimensions in order to dispose of the coming flow from upstream: the flow passes on the grid, it crosses it changing the direction and threading in the holes, and continues towards the downstream, changing to a new direction and, by now, with a reduced kinetic charge. 
The hydraulic operation of the device was studied from Prof. Carlo Viparelli $[8,9]$ which first showed that in relation to the conditions of upstream flow before the grid, and to the geometric characteristics of the dissipator: width, length, slope, number and dimension of the holes, empty-full ratio, various conditions of operation can take place: in slow flow, in fast flow or a flow with localized jump.

The Author supplied moreover some designing norms for the device. In particular, in the case of operation in fast flow, on the base of the following hypotheses: kinetic degree of flow Fr constant and rectilinear profile of the flow along the grid, the length $\mathrm{L}$ can be equal to

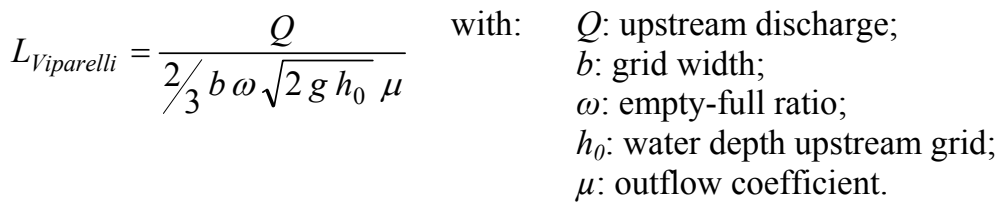

in which the out-flow coefficient $\mu$, function of $\mathrm{Fr}$, can be calculated with the obtained formula $\mu(F r)=0.60 e^{-0.13 F r}$ as a result of successive tests experience [3], and in which the height of the sides of the channel that receives the grid can be established in function of the flow profile that is established along the grid.

The grid length can eventually be reduced blocking the final section of the grid [8]; such expedient, as it will become later cleared, supports the formation of macro turbulences.

The effectiveness and the efficiency of the aforesaid grid device to the aim of the reduction of the kinetic charge of clear water flows, have been subsequently verified experimentally on more models in reduced scale of works to service artificial lake drainages prepared in the Laboratory of the Department from Viparelli $[8,9]$ before and then from De Martino et al. [3]. This last one, in particular, leads an experimental research on a physical model in scale 1:30 of the device of dissipation to service the surface weir drainage of the Cesima tank of the surge system of Presenzano.

Sizing problems induced to reduce the length of the grid to a quarter of a that calculated with the Viparelli theory, being arranged as an obstruction wall downstream; the empty-full ratio was fixed to approximately 0.30 and the dimensions of the holes were established also taking into account the eventual necessity to leave space for larger debris carried by the flow.

Therefore the grid, of rectangular shape in the model, was $72 \mathrm{~cm}$ long (equal therefore in scale 1:30 to $L=L_{\text {Viparelli }} / 4$ ) and $30 \mathrm{~cm}$ wide, with ten lines of six holes of rectangular section $(4.33 \times 2.33 \mathrm{~cm})$ and an obstruction wall downstream.

The tests concluded that the grid dissipator can be used with good results. In particular: for the rectangular shape holes which were the most effective opportune values of the empty-full ratio comprising of between 0.25 and 0.30 ; the length of the grid can be much more limiting regarding that one deductible from the Viparelli theory blocking, like that suggested from the same Author, the down extremity with a wall able to favor the formation of macro turbulences that increase the dissipative effectiveness. 
From the idea to use an analogous dissipator for the dissipation of the kinetic charge of a mud-flows it is part of the successive research, still in progress, first results of which were illustrated into a previous work [4], and that is, in part, the object of the present job, to estimate the eventual effectiveness in terms of energetic dissipation also in the case of fast mud-flows.

\section{Experimental installation: bottom grid with obstruction wall}

Using the grid of the physical model of Cesima dissipator, previously described, an experimental prototype was prepared to simulate the phenomenon of mudflows and the eventual dissipation of energy.

The experimental installation (Fig. 1) is made up of a steel basin, of approximately $1000 \mathrm{l}$, with a particular pumping group that is able to raise a mud-flow of up to $30 \mathrm{l} / \mathrm{s}$ to a maximum height of approximately $12 \mathrm{~m}$.

The basin is equipped with a recirculating system that guarantees an adapted homogeneity to the water and solid part mixture.

A flexible PVC pipe (lousiana) of $120 \mathrm{~mm}$ diameter, that feeds a rectangular channel with a width of $30 \mathrm{~cm}$ and sides of $15 \mathrm{~cm}$ height such to contain the maximums levels that the flow can reach on the grid, exits from the basin. The channel initially has a slope of $40 \%$, shaping itself like a slide with a grid at its lower part, realized in Plexiglas (Fig. 2) and arranged with horizontal slope. To the end part of the grid is placed an obstruction wall with a cover that avoids the spillage of the mud and favours also the formation of macroturbulences which further help clear the flow. Under the grid there is a channel that collects the mud and takes it inside the basin, allowing the recycle.

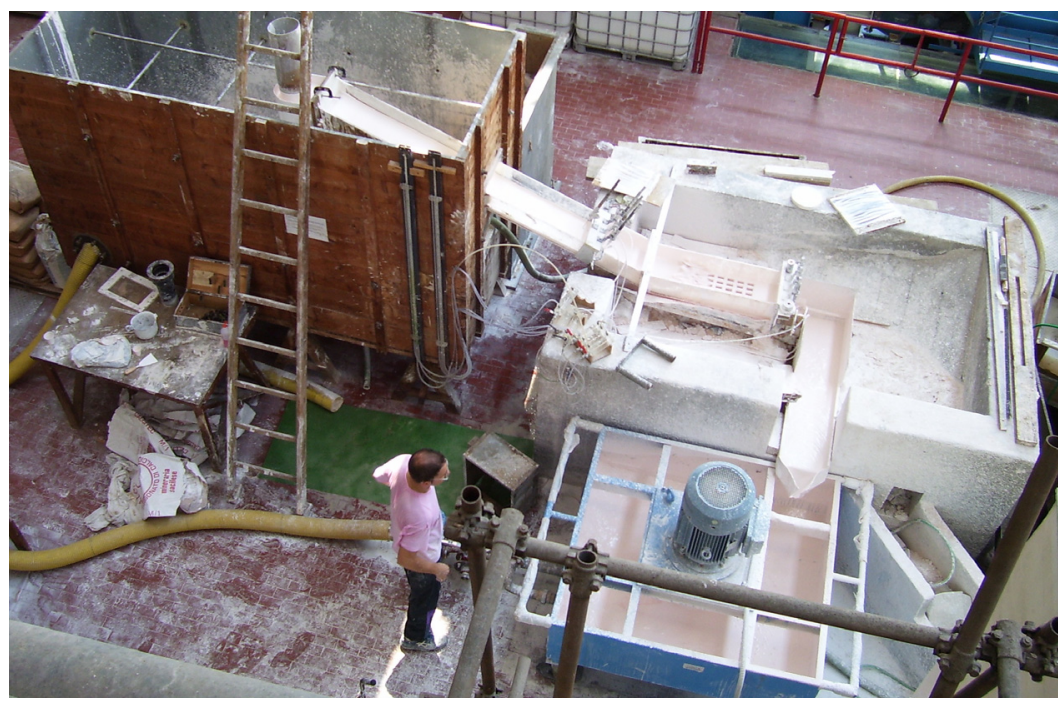

Figure 1: Experimental installation. 
For the measurement of the flow speed and the consequent esteem of the dissipative effect of the device, there has been arranged two groups of three pitot tubes in each one. The first group is placed after the slide, immediately upstream of the grid, and the second one immediately down-stream, in the channel of the collected mud (Fig. 2).

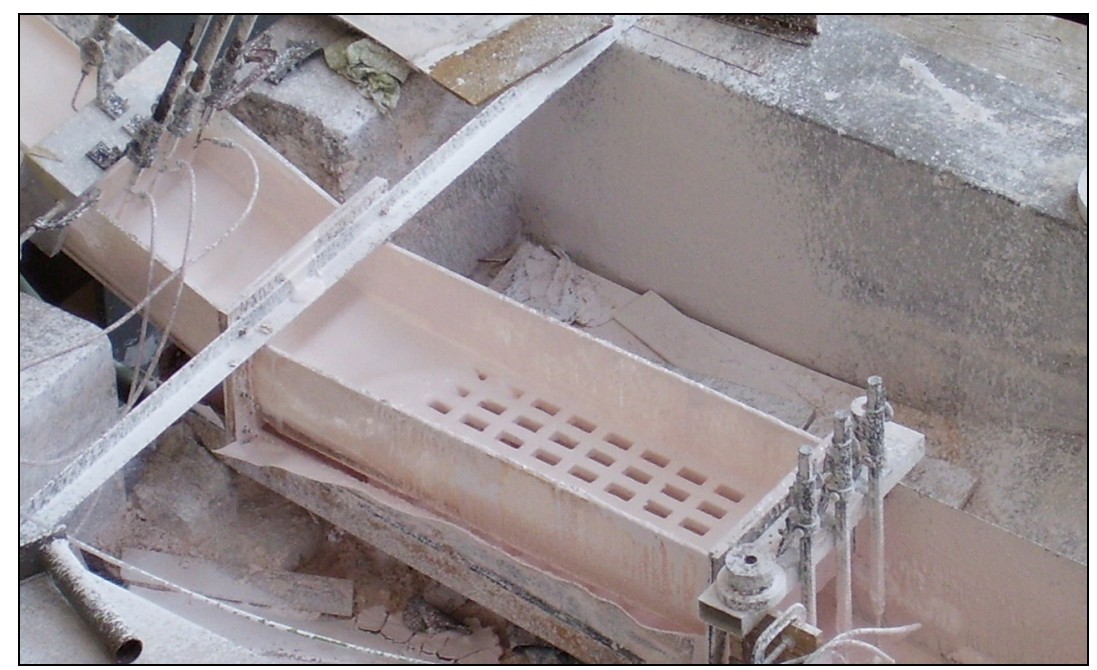

Figure 2: View of the grid, up-stream and down-stream groups of Pitot tubes.

A hydraulic system is planned for measuring the muddy current kinetic load (connecting each pitot tube with the relative hydrometer) and for, when necessary, washing the small tubes (connecting each pitot tube with the washing circuit). Finally, in the section up-stream of the grid, in correspondence of the central pitot tube, a hydrometer has been placed for estimating the level (and, therefore, the flow) of the incoming muddy current.

To create the muddy mixture calcium carbonate (CALCITEC M/1) has been used, characterized by the grain curve of Fig. 3 .

Calcium carbonate has been used because it is practically insoluble in water, generating a homogenous mixture and leaving at the bottom, while the pump is operating, only a small percentage of easily removable residue.

The choice of the characteristics of the mixture has been carried out taking into account studies on physical models of works that have been realized for the mitigation of hydro-geologic risk in the zones of the Campania hit from the alluvium of 5-6 May 1998 [5]. The characterization of the river bed material in such studies has allowed the characteristics for the mud used for this experimentation to be established: with the specific weight of material 430 $\mathrm{kg} / \mathrm{m}^{3}$, pressed specific weight $600 \mathrm{~kg} / \mathrm{m}^{3}$ and $d_{50}$ equal to $0.0013 \mathrm{~mm}$ (Fig. 3). The chosen values can be representative of a real mud that attended the dimensions of the prototype and could be defined on the following studies of the scale problems that will be the object of further papers. 


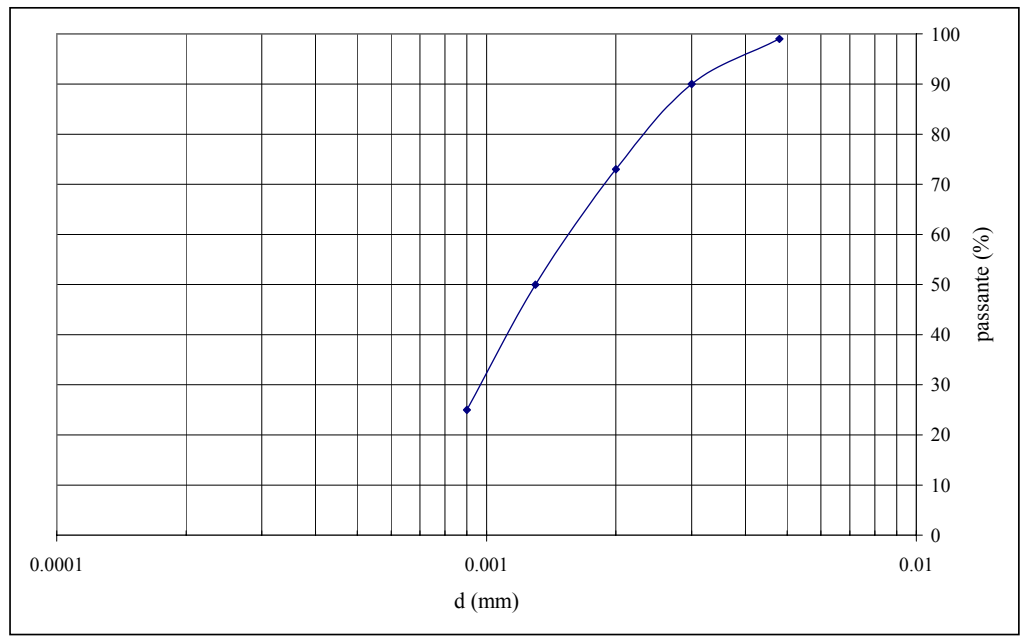

Figure 3: $\quad$ Grain curve of the utilized material (CALCITEC M/1).

In the course of the tests, variable values of volume concentration have been adopted of between $50 \%$ and $70 \%$, and it has been provided to characterize the mixture by continuous measures of specific weight and viscosity.

\section{Results analysis}

The experimental tests have been executed maintaining the approximately constant reologic characteristics of the mixture by subjecting it to a continuous monitoring through viscosity, concentration (in weight) and specific weight measures. For viscosity and specific weight measures, a rotational viscometer type Brooksfield and a precision balance has been used, respectively,

For the valuation of the effectiveness, reference to the percentage speed dissipation has been made, calculated referring to medium values by using the ratio between the difference of up-stream and down-stream speed and the up-stream one (1- $\left.\mathrm{V}_{\text {downstream }} / \mathrm{V}_{\text {upstream }}\right)$.

About the reologic characteristics of the mixture, the dynamic viscosity has been maintained in the field between the values of $0,18 \mathrm{~Pa} \cdot \mathrm{s}$ and $\mathrm{Pa} \cdot \mathrm{s}$, that corresponds to a concentration in weight between $32 \%$ and $34 \%$. The specific weight is approximately equal to $1240 \mathrm{~kg} / \mathrm{m}^{3}$. Within the tests carried out, the Reynolds number is always lower than 500 (the motion can be considered laminar) and the Froude number is included between 7 and 15 .

The first tests have been carried out on the prototype in the configuration given in the previous paragraph, that is with a grid made up of 10 rows each with 6 holes, a length $L=L_{\text {Viparelli }} / 4=72 \mathrm{~cm}$ and an empty-full ratio $\omega=0.30$. The obtained results are shown in Fig. 6 that displays the speed percentage dissipation on the muddy current kinetic degree incoming the grid, expressed through the Froude number $\left(F r=V_{\text {upstream }} / \sqrt{g h_{\text {upstream }}}\right)$. 
They evidence that the dissipative capability of the device grows in a nonlinear way to the increasing medium kinetic charge of the up-stream muddy flow and that the dissipation substantially depends on two phenomena: the first linked to the grid-effect that imposes to the current a double change of direction and the second, instead, to the impact of the same flow on the obstruction wall that involves a conspicuous loss of energy. In particular, it can be seen from the tests that for lower kinetic degree values $(\mathrm{Fr}=7 \div 10)$ of incoming muddy flow to the device, the energy dissipation is due mainly to the grid-effect since the current reaches the end of this one with a reduced energy so that it does either not hit, or only softly hits the obstruction wall; for greater values of kinetic degree $(\mathrm{Fr}=10 \div 15)$, instead, the flow hits the wall at the end of the grid. In such cases, therefore, the grid-effect is summed to the wall-effect, obtaining a meaningfully higher total dissipation catching up the maximum values of $65 \%$ in terms of speed.

Subsequent tests have been carried out in order to estimate influence on device effectiveness and efficiency of the two main planning parameters of the grid: the length $(L)$ and the empty/full ratio $(\omega)$.

In order to know the influence of the grid length it has been reduced, leaving constant the empty/full ratio. In particular, configurations (2) and (3) have been examined. They have the following characteristic:

- (2): grid made up of 8 rows each with 6 holes $\left(\omega_{(2)}=0.30, L_{(2)}=0.8 L\right)$;

- (3): grid made up of 6 rows each with 6 holes $\left(\omega_{(3)}=0.30, L_{(3)}=0.6 L\right)$.

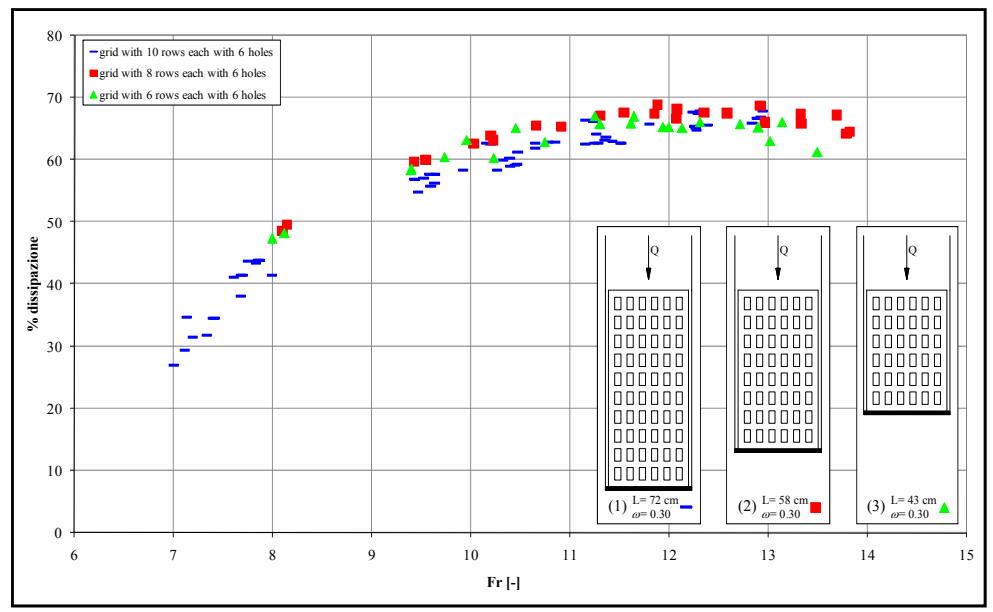

Figure 4: Dissipative capability of the device in function of current average speed.

In Fig. 4, the results for configurations (2) and (3) and the previous one (1) are shown.

By tests carried out, it can be deduced that a further length reduction does not involve a substantial dissipative increment but only a substantial elevation of water levels with eventual risks for the sidewalls overtopping. 
Therefore, a further total length reduction does not appear from the tests executed which is advisable because it would be necessary to elevate the sides in order to avoid the overtopping.

From experimental observation of the dissipative phenomenon, in correspondence of the wall, the beneficial effect of a full band at the end of the grid, next to the obstruction wall, was guessed. This solution can, in fact, favour formation of macro-turbulences that increase the total dissipative ability.

Following tests, therefore, have been finalized to the analysis of the full band influence, with $\omega$, on the dissipation efficiency. At the beginning the grid has been modified to obtain three new configurations analogous to previous ones $((1),(2),(3))$ but with the presence of an approximately $9.4 \mathrm{~cm}$ full bend at the end of the grid. Leaving length constant and reducing the number of holes, there's a reduction of the empty-full ratio; so the analyzed configurations are:

- (1a): grid made up of 9 rows each with 6 holes, with terminal short full bend $\left(\omega_{(1 \mathrm{a})}=0.27, L_{(1 a)}=L, l_{(l a)}=0.13 L_{(l a)}\right)$;

- (2a): grid made up of 7 rows each with 6 holes, with terminal short full bend $\left(\omega_{(2 \mathrm{a})}=0.26, L_{(2 a)}=0.8 L, l_{(2 a)}=0.16 L_{(2 a)}\right)$;

- (3a): grid made up of 5 rows each with 6 holes, with terminal short full bend $\left(\omega_{(3 a)}=0.24, L_{(3 a)}=0.6 L, l_{(3 a)}=0.22 L_{(3 a)}\right)$.

Results are shown in Fig. 5. It can be seen that there is a clean superimposition among the three configurations curves.

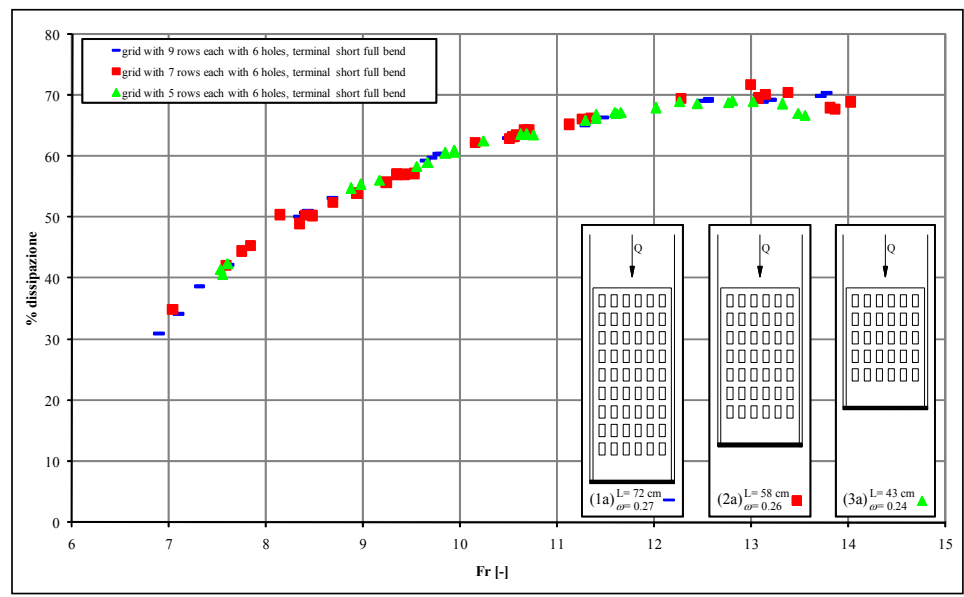

Figure 5: Dissipative capability of the device in function of current average speed (configurations with short full band).

From the results of the configurations (1), (2), (3) and (1a), (2a), (3a) it can be seen that:

- dissipation at configuration (1) is low in the examined kinetic degree field of a quantity on average of $3 \%$ in comparison with all the others;

- all values relative to all configurations, with the exception of the (1), substantially are overlapped until $\mathrm{Fr}=12$; 
- beyond this value, the distributions (1a), (2a) and (3a) remain however overlapped but are higher than the others, (2) and (3), of a quantity on average of $3 \%$.

From these realizations it can be deduced that:

- in configuration (1) the dissipation is substantially entrusted to the grid effect that guarantees a maximum percentage dissipation of approximately $65 \%$;

- in configurations (2) and (3) the wall effect takes part too; it improves the dissipative ability of device until to maximum value of approximately $67 \%$;

- in the configurations (1a), (2a) and (3a) the maximum dissipation reach the $70 \%$ approximately, thanks to another dissipative phenomenon that is due to formation of horizontal axis vortices, as before guessed.

In fact the presence of the full band at the end of the grid, the obstruction wall next to its and the upper cover, favours the formation of macro turbulence processes (horizontal axis vortices or rollers) (Fig. 6); such vortices are settled in proximity of the obstruction wall and, absorbing a more or less conspicuous share of the kinetic energy, determine an elevated loss of total energy.

In conclusion it can be asserted that the presence of a full band, on the whole, induces an improving effect of efficiency on which the reduction of the total length of the grid is not influential, except for the increment of water levels.

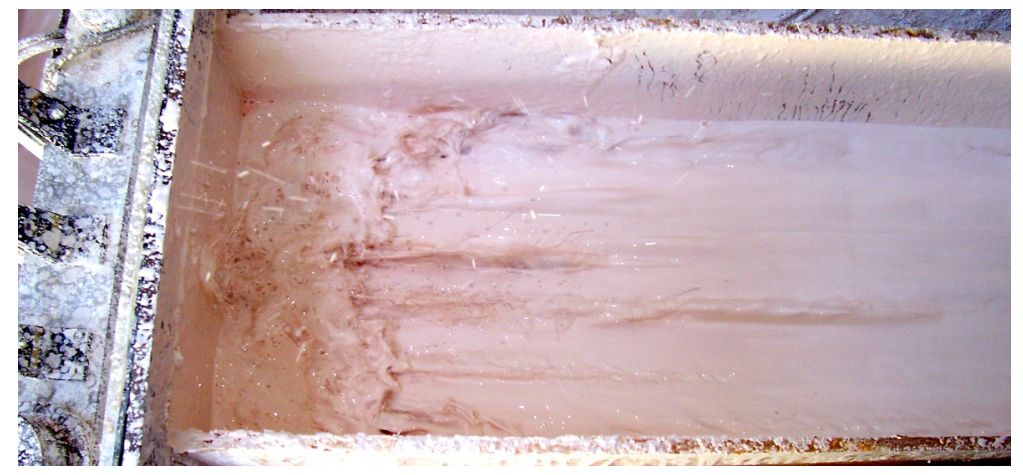

Figure 6: View of a roller.

Subsequently the length of full bend has been increased carrying it to approximately $17 \mathrm{~cm}$; such operation has analogous before involved a reduction of $\omega$. The analyzed configurations, therefore, are:

- (1b): grid with 8 rows of 6 holes with long full bend of downstream $\left(\omega_{(1 b)}=0.24, L_{(l b)}=\mathrm{L}, l_{(l b)}=0.23 L_{(l b)}\right)$;

- (2b): grid with 6 rows of 6 holes with long full bend of downstream $\left(\omega_{(2 b)}=0.22, L_{(2 b)}=0.8 L, l_{(2 b)}=0.28 L_{(2 b)}\right)$;

- (3b): grid with 4 rows of 6 holes with long full bend of downstream $\left(\omega_{(3 b)}=0.19, L_{(3 b)}=0.6 L, l_{(3 b)}=0.38 L_{(3 b)}\right)$.

The tests results are brought back in Fig. 7 from which it is possible to deduce a clean overlap between the values of the three configurations under investigation. The ulterior increase of $l$ (and consequent reduction of $\omega$, in this 
case, do not influence in an important way on the device efficiency. In fact, overlapping the results with those of the configurations (a), overlap not exemplified for space reason, finds a light increment of the dissipative capacity to the order of $2 \%$.

If relatively to the dissipative capacity the configurations (1b), (2b) and (3b) have the same behavior, that does not happen relatively to the motion conditions that the muddy current assumes along the grid. In fact, the tests have been able to show that the hydraulic behavior of the current in the configuration (1b) is analogous to that one of the configurations (a), with short full bend, so the three effects co-exist: grid, wall and rollers. In the configurations (2b) and (3b), instead, the conditions of motion in the channel that receives the grid change and the current passes from fast to slow with the consequent formation of a hydraulic jump. In this case the great part of the dissipation must be attributed to the formation of the jump that gives to the current a large part of the energy.

Such operation must be avoided for two reasons:

- the slow current that is downstream of that jump assumes water levels much more elevated than those connecting to the fast current where, instead, there would be a jump absence and regarding which, the height of the sides of the channel that receives the grid has been calculated;

- the formation of the jump induces some depressions on the surface of the grid such to eventually being able to offend the integrity of the structure.

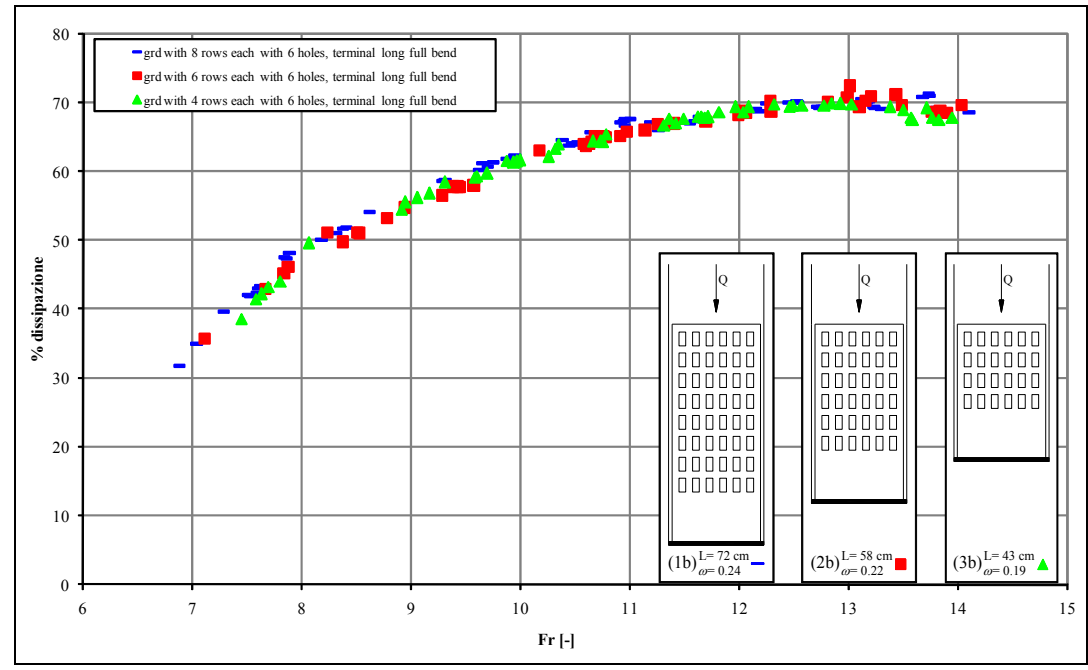

Figure 7: Dissipative capability of the device in function of current average speed (long full band).

It can be concluded that, at least for the experiences carried out, the configuration that guarantees the better operation (fast current) and at the same time the greater dissipation percentage (maximum dissipation $72 \%$ ) is (1b) characterized by length $L$, and $l=0.23 L$. 
Later on it has been verified that the eventual influence of the longitudinal slope of the grid placed leaning in the direction of the mud-flow motion. Relative to the grid that has given the best results in a horizontal position, constituted by 8 rows of 6 holes with long full downstream bend (1b), the slope is assigned by $10 \%$ and subsequently of $20 \%$. A small improvement to the dissipation is reached in the order of $5 \%, 8 \%$ and is indistinct between the position at $10 \%$ and $20 \%$ of slope.

Given the small improvement in terms of dissipation, the positioning in the slope of the grid would be justifiable, in the real case, only when orography of the places allowed assigning a slope to the dispositive without excessive constructive burden.

\section{Preliminary design criteria}

For a preliminary sizing of a grid dissipator for mud-flows with an obstruction wall, the design flow, the known water level to the entrance of the grid, it is possible to proceed as follows:

- the Viparelli theory is applied and therefore, with the (1), the grid length $L_{\text {Viparelli }}$ is estimated fixing an empty/full ratio equal to approximately 0.25 (in the tests 0.24);

- arranging the obstruction wall to the term of the grid, the obtained length is reduced until $1 / 4$ and therefore the effective grid length becomes equal to $L=L_{\text {Viparelli }} / 4$;

- the terminal grid part is computed as full bend equal to approximately $25 \%$ of $L$ (in the tests $23 \%$ ).

Lastly, if the morfologic conditions of the places allow the in slope positioning of the grid, it can also be convenient to assign some slope to the device obtaining a small improvement in dissipation.

\section{Final considerations}

In the present paper the results of an experimental test on a grid dissipator with obstruction wall was finalized to investigate the efficiency of them in terms of the mud-flow kinetic charge dissipation. The tests, carried out near the Laboratory of Department of Hydraulic and Environmental Engineering "G. Ippolito" of Naples, have regarded the behavior of the dissipator by varying the grid length, the downstream full bend dimension and varying the upstream current speed. The preparation of the prototype, used for the tests, has been based on the indications that have been obtained by previous theoretical studies on reduced scale models of constructions then realized for the clear water operation.

The experimental results about muddy current are satisfactory because they evidence, equal to clear water case, a good dissipative efficiency that can give a maximum of approximately $75 \%$ in terms of speed dissipation or, analogous, to $85 \%$ in terms of kinetic charge dissipation.

Three fundamental effects that characterize the dissipation phenomena have been pointed out: the grid effect that imposes to the current a double direction change, the wall effect which had an impact of the current on the obstruction 
final wall and the effect which had to the rollers formation. The grid effect is preponderant on the others for configurations with grid length greater or, analogous, for modest upstream current speed; the wall effect manifests itself for reduced grid length or, analogous, growing of the speed; the rollers creation, at last, is due to two concomitant conditions: the presence of full bend (that involves a $\omega$ reduction) and that one of the obstruction wall with annexed cover wall. It has been observed moreover that when the full bend length becomes a substantial share $(>30 \%)$ of the total grid length, the current passes from fast to slow with consequent creation of a hydraulic jump. Such conditions should be minimized to avoid overtopping.

\section{References}

[1] Armanini A., Darlì C., Della Putta F., Larcher M., Sartori F., (2004). “Opere diffuse per la difesa dalle colate di fango". Atti del $29^{\circ}$ Convegno Nazionale di Idraulica e Costruzioni Idrauliche, Trento.

[2] De Martino G., Gisonni C., Giugni M., (2002). “Tipologie di interventi per la mitigazione dal rischio idrogeologico". Atti della Giornata di Studio in onore di Lucio Taglialatela, Napoli.

[3] De Martino G., Giugni M., Pulci Doria G., (1994). "Su un particolare tipo di dissipatore a griglia: primi risultati sperimentali". XXIV Convegno di Idraulica e Costruzioni Idrauliche, Napoli.

[4] De Martino G., De Paola F., Fontana N., Giugni M., (2005), “Analisi sperimentale del comportamento di un dispositivo a griglia per la dissipazione del carico energetico di una colata di fango" in Atti Convegno Nazionale La mitigazione del rischio da colate di fango a Sarno e negli altri Comuni colpiti dagli eventi del maggio 1998, Napoli, 2 e 3 Maggio 2005 Sarno 4 e 5 Maggio 2005

[5] CUDAM, Verifica su modello físico in scala ridotta delle opere per il rimodellamento del versante tra il vallone Connola e il vallone S. Francesco in località Quindici - Relazione Finale, 2002

[6] Mizuyama T., Yazawa A., (1987), "A computer simulation for debris flow processes", Erosion and sedimentation in Pacific Rim, Proceedings of the Corvallis Symposium, IAHS pubbl. N. 165.

[7] Versace P., (2001). "La riduzione del rischio idrogeologico nei comuni colpiti dagli eventi del maggio '98 in Campania”. Atti del Forum per il Rischio Idrogeologico in Campania - Fenomeni di colata rapida di fango nel maggio '98, Commissariato di Governo per l'Emergenza Idrogeologica in Campania, Napoli.

[8] Viparelli C., (1961). "Dissipatori a griglia di fondo". Pubblicazione n. 148 dell'Istituto di Idraulica e Costruzioni Idrauliche dell'Università di Napoli.

[9] Viparelli C., (1963). "Dissipatori a griglia di fondo”. L’Energia Elettrica, 7. 